\title{
Exceptional bone density DXA values of the rostrum of a deep-diving marine mammal: a new technical insight in the adaptation of bone to aquatic life
}

\author{
Alessandro Zotti • Roberto Poggi • Bruno Cozzi
}

Received: 18 December 2008 /Revised: 30 December 2008 / Accepted: 3 January 2009/Published online: 6 February 2009

(C) ISS 2009

The use of dual energy X-ray absorptiometry (DXA) to measure bone mineral density (BMD) has been applied to several animal species to examine bone and body composition in longitudinal studies. Although the rat is the most frequently used mammal in DXA-based investigations, the BMD of several species of larger-sized nonhuman mammals has already been reported [1]. Studies on a single specific bone or total body BMD have been performed on nonhuman primates [2, 3], sheep [4], bovine calves [5, 6], horses [7], pigs [8], dogs [9, 10], cats [11], and striped [12] and bottlenose dolphins [13]. All BMD values (expressed as $\mathrm{g} / \mathrm{cm}^{2}$ ) obtained from the species listed above ranged between 0.463 (canine III metacarpal bone) and 2.12 (pig skull). Other values to consider for reference are 1.1 (dolphin arm) and 1.85 (equine III metacarpal bone). In terrestrial mammals, the most important intraspecific factors affecting BMD are body weight and age, whereas in aquatic mammals, the arm and forearm BMD correlated to body dimensions and age of the animal [10-13].

\section{A. Zotti $(\bowtie)$}

Department of Veterinary Clinical Sciences, Radiology Unit,

Viale dell'Università 16, University of Padua,

35020 Legnaro, Padua, Italy

e-mail: alessandro.zotti@unipd.it

R. Poggi

"G. Doria" Civic Museum of Natural History,

Via Brigata Liguria 9,

16121 Genova, Italy

B. Cozzi

Department of Experimental Veterinary Sciences,

Viale dell'Università 16, University of Padua,

35020 Legnaro, Padua, Italy
For the first time, we radiographed the whole skull and scanned by means of a DXA device (Hologic QDR1000, Hologic Inc., Waltham, MA, USA) the rostrum of a male Blainville's beaked whale Mesoplodon densirostris (Blainville, 1817). This specimen was found stranded by Lamberto Loria in Papua New Guinea (ex British New Guinea) at the end of nineteenth century and is now preserved at the "G. Doria" Civic Museum of Natural History in Genova (Italy) with the number MSNG 16. The rostrum of $M$. densirostris is made up by maxillary and premaxillary bones, pterygoids, palatines, and vomer and in mature animals is supported axially by ossification of the mesorostral canal. In adult males, the mesorostral ossification is due to the gradual replacement of mesethoid cartilage with secondary bone [14]. The rostrum consists of dense Haversian tissue, the secondary osteons of which are oriented longitudinally, themselves constituted by hypermineralized parallel-fibered osseous tissue [15]. The ultrastructure of the walls of the secondary osteons is characterized by a strong volumetric reduction of the collagenous network, composed by very thin fibrils oriented longitudinally. The biomechanical behavior of the rostrum is that of an exceptionally rigid, hard but also apparently fragile material [15]. The BMD values of this bone $\left(2.612\right.$ to $\left.2.686 \mathrm{~g} / \mathrm{cm}^{3}\right)$ obtained by simple measurements based on Archimedes's principle have been reported as the highest values hitherto observed for mammalian bone and the rostral mineralization has been quantified up to $22 \%$ above that of "normal" adult mammalian bone [15].

We divided the scan of our specimen into three regions of interest (RoI) because the length of the bone exceeded the DEXA-arm motion track (approximately $70 \mathrm{~cm}$ ). The proximal (pRoI), medium (mRoI), and distal RoI (dRoI) were then scanned in a dorsoventral projection starting from infraorbital foramina toward the foremost extremity of 
the rostrum, each corresponding to $1 / 3$ of the rostrum length.

The data we obtained, expressed as $\mathrm{g} / \mathrm{cm}^{2}$, were (1) $\mathrm{pRoI}=3,245$, (2) $\mathrm{mRoI}=4,481$, and (3) $\mathrm{dRoI}=3,543$. We are aware that as a consequence of the regional analysis of the rostrum, we cannot obtain its precise and accurate global average BMD; however, all the above regional values and especially that referred to the $\mathrm{mRoI}$ indicate by far the highest DXA density ever recorded for any species (almost twice than the highest value previously reported for a living structure). Furthermore, the inner portions of each scanned region showed even more high values than those reported for the corresponding global regional area $(4,913$, 5,701 , and $5,024 \mathrm{~g} / \mathrm{cm}^{2}$, respectively).

The hypothesis of an artifactual result is unlikely, because (1) the accuracy and precision of our device is checked on a regular basis by means of its own calibration phantom (Hologic Calibration Phantom, Hologic Inc., Waltham, MA, USA), (2) although the exceptionally dense values we obtained are "out of scale" referring to the "normal" mammalian values, a specific function for prosthetic analysis of the software in use allowed us to analyze as bone also the densest part of the specimen (Analysis Software Version 6.20 D, Hologic Inc., Waltham, MA, USA), and (3) the scan of the pRoI was repeated with repositioning of the specimen for control and the coefficient of variation resulted less than $1 \%$. Moreover, close gross and radiographic scrutiny of the skull indicate the absence of bone pathologies or mineralization disorders. Obviously, the extremely high density of the rostral bones resulted evident also at radiographic examination.

We are aware that the data we report here could not represent the average values of BMD of the rostrum of the male gender of $M$. densirostris. Unfortunately, this is the only specimen available in our country (and an extremely rare species in Mediterranean waters) so the lack of further information cannot be supplied at present time.

Possible functional explanations for such bone density in male specimens of the Blainville's beaked whale may include (a) the capability to sustain the full brunt of head-on fighting that occurs in males, possibly even at considerable depths, and (b) suction feeding in fish and squid hunting, a process in which the powerful muscle insertions that are typical of males (that are not able to fully open their mouth because of the position of the huge single pair of mandibular teeth) require robust skeletal basis. On the other hand, the diving habits of this species [16] (capable of long foraging dives below 1,400 m under sea level) should not be considered as a specific factor. In fact, the presence of areas of extremely high density in the fore skull may facilitate fast perpendicular descent, thus reducing breathholding times that already exceed the theoretical aerobic limits [17], but other beaked whales dive deeper and show no comparable bone density in the rostrum. The role of superdense bone in the peculiar patterns of echolocation typical of this species remains to be investigated [18].

The aim of our report is to give a new and technically sound insight in the actual relationship existing between the bone density of the "normal" mammalian bone and that of the already known mammal with the densest bone ever recorded. Finally and specifically important for biological applied investigations, we would like to stress that our results have been obtained with a modern noninvasive technique, routinely used in hospitals for the control of human metabolic bone diseases. Therefore, this updated and readily available technique can be safely applied to museum specimens without risk of damaging unique and valuable materials. Further researches on the accuracy and precision of the technique are mandatory for the prosecution of such studies.

\section{References}

1. Grier SJ, Turner AS, Alvis MR. The use of dual-energy X-ray absorptiometry in animals. Invest Radiol 1996; 31: 50-62.

2. Jayo MG, Jerome CP, Lees CJ, Rankin SE, Weaver DS. Bone mass in female cynomolgus macaques: a cross-sectional and longitudinal study by age. Calcif Tissue Int 1994; 54: 231-236.

3. Jayo MG, Rankin SE, Weaver DS, Carlson CS, Clarkson TB. Accuracy and precision of lumbar bone mineral content by dualenergy X-ray absorptiometry in live female monkeys. Calcif Tissue Int 1991; 49: 438-440.

4. Pouilles JM, Collard F, Tremollieres F, et al. Accuracy and precision of in vivo bone mineral measurements in sheep using dual-energy X-ray absorptiometry. Calcif Tissue Int 2000; 66: 70-73.

5. Nüske S, Scholz AM, Förster M. Studies on the growth of the claws in new born calves using dual energy X-ray absorptiometry (DEXA). Proceedings of the 12th international symposium on lameness in ruminants, Orlando (FL), USA; 2002: 199-201.

6. Scholz AM, Nüske S, Förster M. Body composition and bone mineralization measurement in calves of different genetic origin by using dual-energy X-ray absorptiometry. Acta Diabetol 2003; 40: S91-S94.

7. Carstanjen B, Duboeuf F, Detilleux J, Lepage OM. Equine third metacarpal bone assessment by quantitative ultrasound and dual energy X-ray absorptiometry: an ex vivo study. J Vet Med A Physiol Pathol Clin Med 2003; 50: 42-47.

8. Mitchell AD, Scholz MG, Pursel VG. Total body and regional measurements of bone mineral content and bone mineral density in pigs by dual energy X-ray absorptiometry. J Anim Sci 2001; 79: 2594-2604.

9. Emmerson TD, Lawes TJ, Goodship AE, Rueux-Mason C, Muir P. Dual-energy X-ray absorptiometry measurement of bonemineral density in the distal aspect of the limbs in racing Greyhounds. Am J Vet Res 2001; 61: 1214-1219.

10. Zotti A, Isola M, Sturaro E, Menegazzo L, Piccinini P, Bernardini D. Vertebral mineral density measured by dual-energy X-ray absorptiometry (DEXA) in a group of healthy Italian Boxer dogs. J Vet Med A Physiol Pathol Clin Med 2004; 51: 254-258.

11. Lauten SD, Cox NR, Baker GH, Painter DJ, Morrison NE, Baker HJ. Body composition of growing and adult cats as measured by use of dual energy X-ray absorptiometry. Comp Med 2000; 50: 175-183. 
12. Guglielmini C, Zotti A, Bernardini D, Pietra M, Podestà M, Cozzi B. Bone density of the arm and forearm as an age indicator in stranded specimens of the striped dolphin (Stenella coeruleoalba). Anat Rec 2002; 267: 225-230.

13. Butti C, Corain L, Cozzi B, et al. Age estimation in the Mediterranean bottlenose dolphin Tursiops truncatus (Montagu, 1821) by bone density of the thoracic limb. J Anat 2007; 211: 639-646.

14. McLeod CD. Possible functions of the ultradense bone in the rostrum of Blainville's beaked whale (Mesoplodon densirostris). Can J Zool 2002; 80: 178-184.

15. De Buffrenil V, Zylberberg L, Traub W, Casinos D. Structural and mechanical characteristics of the hyperdense bone of the rostrum of Mesoplodon densirostris (Cetacea, Ziphiidae): summary of recent observations. Hist Biol 2000; 14: 57-65.

16. Baird RW, Webster DL, McSweeney DJ, Ligon AD, Schorr GS, Barlow J. Diving behaviour of Cuvier's (Ziphius cavirostris) and Blainville's (Mesoplodon densirostris) beaked whales in Hawaii. Can J Zool 2006; 84: 1120-1128.

17. Tyack PL, Johnson M, Aguilar de Soto N, Sturlese A, Madsen PT. Extreme diving of beaked whales. J Exp Biol 2006; 209: 42384253.

18. Johnson M, Madsen PT, Zimmer WMX, Aguilar de Soto N, Tyack PL. Foraging Blainville's beaked whales (Mesoplodon densirostris) produce distinct click types matched to different phases of echolocation. J Exp Biol 2006; 209: 5038-5050. 